\title{
Intensification of synthesis processes of clinker minerals in presence of coal-alkaline additive
}

\author{
Natalia Petrovna Bushueva \\ Department of glass and ceramics technology, \\ Belgorod State Technological University \\ named after V.G. Shukhov \\ BSTU named after V.G. Shukhov \\ Russia
}

\author{
Olga Aleksandrovna Panova \\ Department of glass and ceramics technology, \\ Belgorod State Technological University \\ named after V.G. Shukhov \\ BSTU named after V.G. Shukhov \\ Russia \\ e-mail: pipp@mail.ru
}

\author{
Pavel Vasilievich Besedin \\ Department of glass and ceramics technology, \\ Belgorod State Technological University \\ named after V.G.Shukhov \\ BSTU named after V.G.Shukhov
}

Russia

\begin{abstract}
When preparing cement raw slurry, in order to regulate its aggregative stability and flowability, a coal-alkaline additive is used, which not only changes the surface properties of disperse particles, but also intensifies the portland cement clinker synthesis process. Adding of coal-alkaline reagent into the raw mix allows not only reducing the viscosity of the slurry and improving its fluidity, but also lowering the temperature of clay minerals dehydration and $\mathrm{CaCO}_{3}$ decarbonization and the substances interaction processes in the solid phase proceed as a result at the temperature under $1250-1270{ }^{\circ} \mathrm{C}$. Thermodynamic calculations have allowed theoretically confirming the efficiency of this additive's application. A considerable amount of the released heat in the temperature interval of $200-452{ }^{\circ} \mathrm{C}$ intensifies the removal of the chemically bound water from clay minerals and contributes to the destruction of their crystalline lattices, which is eventually good for reducing the specific fuel consumption. Thermodynamic calculations have also confirmed the possibility of the formation process of clinker minerals at relatively low temperatures in the presence of the additive and allowed evaluating the role of certain components of the additive in this process. The calculation data of $\Delta \mathbf{G}_{\mathrm{T}}{ }^{0}$ indicate the increase of the system's stability when using coal-alkaline reagent.
\end{abstract}

Key words - minerals, portland cement, coal-alkaline additive, synthesis, dehydration, decarbonization, solid-phase reactions, thermodynamic analysis, heat effect, possibility of formation, stability.

\section{INTRODUCTION}

The research of the components of portland cement clinker raw mix interaction with various additives is of interest for determining the mechanism of physical and chemical processes, which activate minerals formation. The key factor in improving the hydraulic activity of binder's minerals is establishing an inextricable connection with their composition and crystallization structure, which determine the physical, mechanical and performance characteristics of cement-based products [1-3]. The study of the interaction of carbonate and clay raw mixes with compounds, able to activate the silicateforming reactions, reveals the mechanism of the additives' influence on the processes of minerals synthesis.

\section{RAW MATERIALS}

The clays, used in portland cement clinker production, mostly contain montmorillonite, hydromicas, and kaolinite. During ignition, the chemically bound water is removed from these minerals in various temperature ranges [3].

The crystalline structure of kaolinite (fig. 1), dickite and nacrite consist of two-layer packs, which contain one siliconoxygen tetrahedral layer $\left[\mathrm{Si}_{2 \mathrm{n}} \mathrm{O}_{5 \mathrm{n}}\right]^{2 \mathrm{n}-}$ and one aluminumoxygen hydroxyl octahedral layer $\left[\mathrm{Al}_{2 \mathrm{n}}(\mathrm{OH})_{4 \mathrm{n}}\right]^{2 \mathrm{n}+}$. Both layers are united into the pack by the shared oxygen of the siliconoxygen layer. 


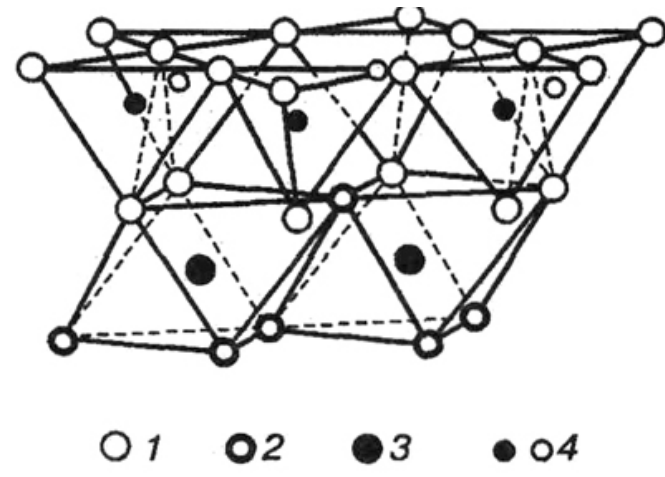

Fig. 1. The structure of kaolinite:

1 - oxygen; 2 - hydroxyl; 3 - aluminium; 4 - silicon

When kaolinite is heated to at temperature of $500-600{ }^{\circ} \mathrm{C}$ the substantial ignition losses are observed due to constitution water emission with the crystalline lattice destruction (loss of hydroxyl ions) and amorphization of the minerals. The first exothermic reaction at $900-1000{ }^{\circ} \mathrm{C}$ is caused by the beginning of mullite, amorphous silica, and sometimes of $\gamma-\mathrm{Al}_{2} \mathrm{O}_{3}$ crystallization. The processes, which take place during the kaolinite heating, proceed according to the following scheme:

$\mathrm{Al}_{2} \mathrm{O}_{3} \cdot 2 \mathrm{SiO}_{2} \cdot 2 \mathrm{H}_{2} \mathrm{O} \rightarrow \mathrm{Al}_{2} \mathrm{O}_{3} \cdot 2 \mathrm{SiO}_{2}+2 \mathrm{H}_{2} \mathrm{O} \rightarrow 3 \mathrm{Al}_{2} \mathrm{O}_{3} \cdot 2 \mathrm{SiO}_{2}+\mathrm{SiO}_{2}$

The clay of the Latnenskoye deposit is a clay, the source mineral of which is kaolinite $(82.14 \%)$ with admixed montmorillonite $(14.12 \%)$. According to DTA method data (fig. 2) in kaolinite clay (of Latnenskoye), the dehydration process takes place in temperature intervals 400-560 and 650$790{ }^{\circ} \mathrm{C}$ (endothermal effects (-) 503.4 and $(-) 751.3^{\circ} \mathrm{C}$ ) (fig. 2 , a). In hydromica-montmorillonite clay (of Belgorod) - 380500, 560-590, 620-680 and 820-890 ${ }^{\circ} \mathrm{C}$ (endothermal effects ()456.6; (-)574.4; (-)642.5 and $(-) 745.8^{\circ} \mathrm{C}$ ) (fig. 2 , b).

The coal-alkaline reagent (USCHR) is a reaction product of milled brown coal $(13 \%)$ with caustic soda or caustic potash $(2 \%)$. It is one of the most efficient, cheap and available reagents. At its heating, the combustible component of LAR is oxidized.

When using the coal-alkaline additive as a surface-active substance to improve the rheological properties of portland cement raw slurry [4], the positive effect is observed not only due to the improvement of the slurry's rheological characteristics, but also due to the intensification of processes, which take place during ignition. The efficiency of the coalalkaline additive has been theoretically and experimentally confirmed; this additive not only increases the fluidity and reduces the viscosity of the raw slurry for portland cement clinker production, but also allows shifting the dehydration process of clay minerals to the lower temperature range [5]. And the amount of the generated heat in the temperature interval $200-452^{\circ} \mathrm{C}$ results in heat energy saving.

\section{EXPERIMENTAL PART}

The analysis of energy consumption changes at the stage of endothermic and exothermic reactions of the raw mix when introducing plasticizing reagents into it allows solving the problem of reducing the moisture of raw cement slurries and the problem of energy saving during clinker burning. The thermal dissociation of $\mathrm{CaCO}_{3}$ is an endothermic process, which goes on with the ingress of heat $(1675-1780 \mathrm{~kJ} / \mathrm{kg}$ $\mathrm{CaCO}_{3}$ ), so the heat consumption in this part of the furnace is the highest [9].
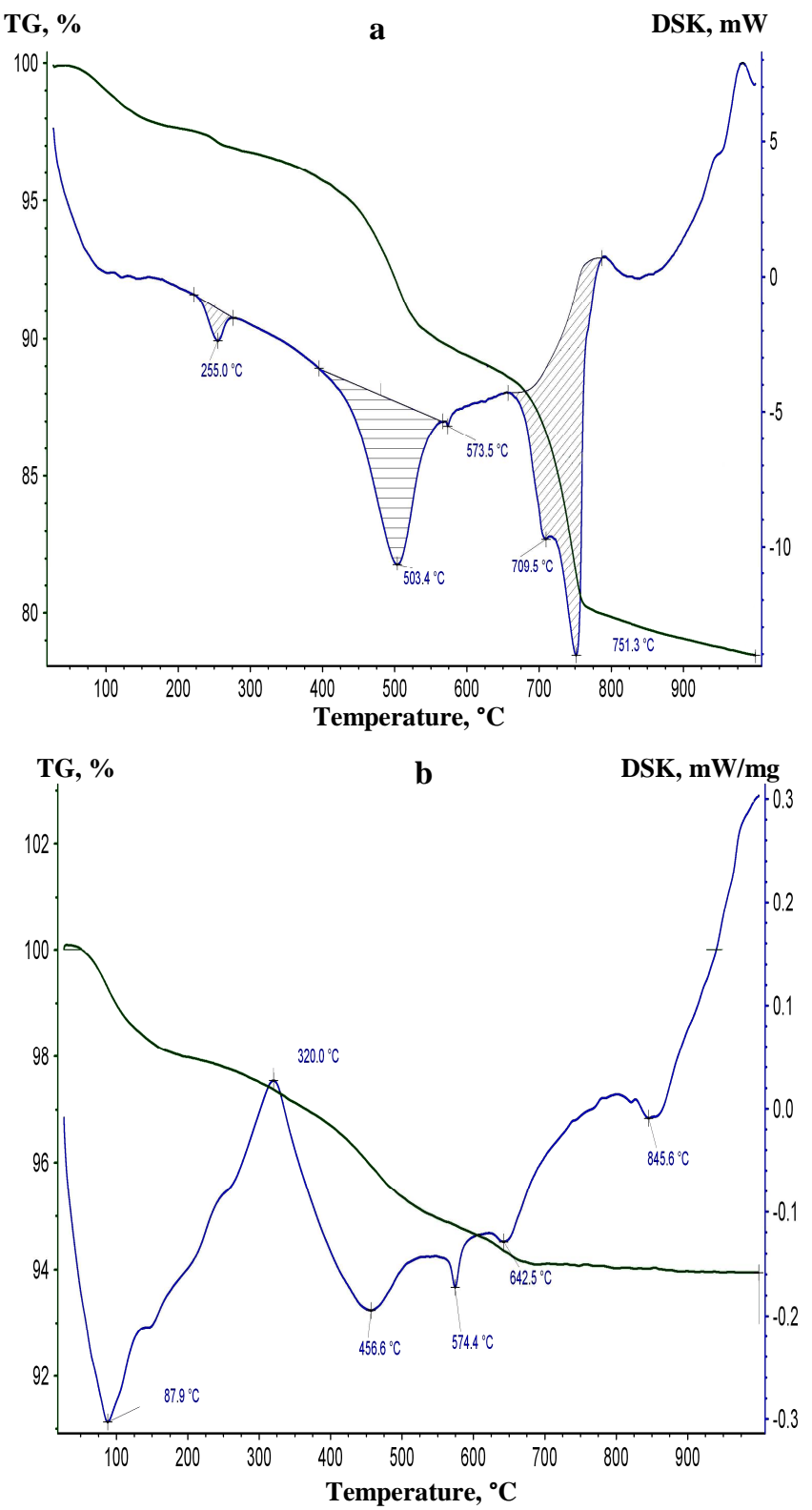

Fig. 2. Thermograms of natural clays: $\mathrm{a}$ - kaolinite clay, $\mathrm{b}$ - hydromica-montmorillonite clay

The burning of the raw mix for obtaining portland cement clinker with introducing 0.9 wt. $\%$ of the additive, containing carbon and sodium hydroxide, intensifies the dehydration process of clay minerals, shifts the decarbonization process to the range of lower temperatures $\left(803.8{ }^{\circ} \mathrm{C}\right)$ and possibly accelerates the interaction of substances in the solid phase. It is confirmed by differential thermal analysis data (fig. 3). The thermogram indicates no endothermic effects of clay minerals dehydration and the endothermic effect of decarbonization shifts to the range of lower temperatures (by $20^{\circ} \mathrm{C}$ ). 
TG, \%

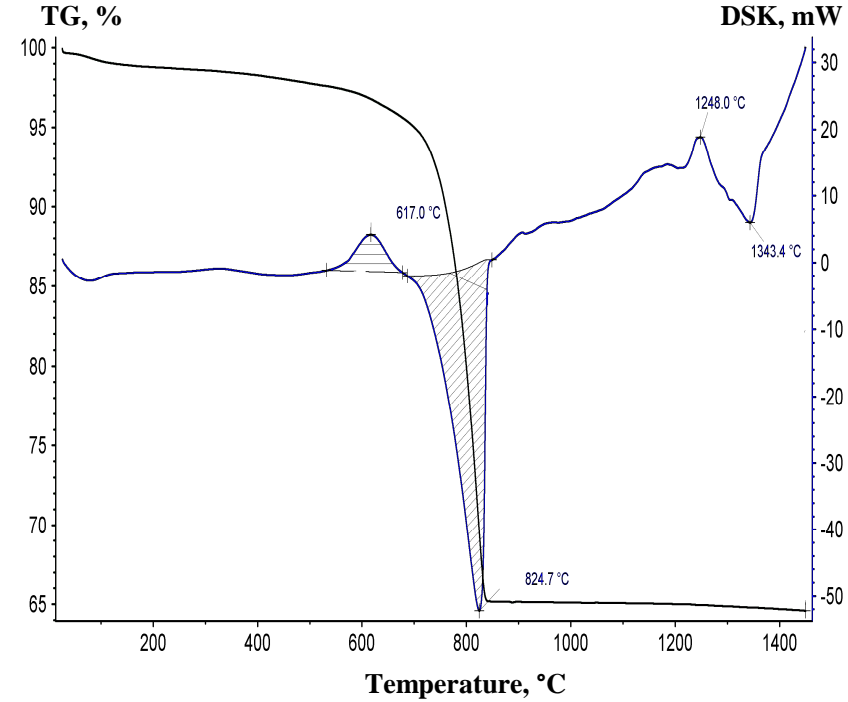

Fig. 3. Thermogram of the raw mix with 0.9 wt. $\%$ of USCHR

The present-day production often uses thermodynamic analysis in designing and selecting the optimal process layouts of raw material processing and material synthesis with the purpose of the preliminary modeling of the technological process [6]. The application of the thermodynamic method of studying the high-temperature processes allows obtaining valuable information about the opportunities of the purposeful conducting of certain reactions and the ways to control the processes.

\section{CALCULATION PART}

The thermodynamic analysis allows supposing the possibility of certain compounds' formation by means of basis reactions $[7,11]$.

To determine the chemical reactions behavior and energy performance at the constant pressure and temperature, the second law of thermodynamics is used, which is written in the form of the following equation:

$$
\begin{gathered}
\Delta \mathrm{G}_{\mathrm{T}}{ }^{\mathrm{o}}=\Delta \mathrm{H}_{\mathrm{T}}^{\mathrm{o}}-\mathrm{T} \Delta \cdot \mathrm{S}_{\mathrm{T}} \text { or } \\
\Delta \mathrm{G}_{\mathrm{T}}{ }^{\mathrm{o}}=\Delta \mathrm{H}^{\mathrm{o}}-\Delta \mathrm{a} \cdot \mathrm{T} \cdot \ln \mathrm{T}-0.5 \Delta \mathrm{b} \cdot \mathrm{T}^{2}-0.5 \Delta \mathrm{c} \cdot \mathrm{T}^{-1}+\mathrm{y} \cdot \mathrm{T},
\end{gathered}
$$

where $\Delta \mathrm{H}^{\mathrm{o}}$ and $\mathrm{y}-$ integration constants.

To calculate the reaction heat at the temperature alteration, the Kirchhoff's equation is used:

$$
\Delta \mathrm{H}_{\mathrm{T}}^{\mathrm{o}}=\Delta \mathrm{H}_{298}^{\mathrm{o}}+\int^{\mathrm{T}}{ }_{298} \mathrm{c}_{\mathrm{p}} \mathrm{dT} \text {. }
$$

To evaluate the energy performance of the complex additive's usage, it is necessary to determine the influence by each of its components. The coal-alkaline additive contains $\mathrm{C}_{67} \mathrm{H}_{67} \mathrm{O}_{30} \mathrm{~N}_{3}(\mathrm{COOH})_{5}$ and $\mathrm{Na}(\mathrm{OH})$ with a carbon content of 8 $\%$ and $\mathrm{Na}(\mathrm{OH})-10-16 \%$. So, when studying the influence of the additive, its components and the percent of appending on the dehydration process of kaolinite, as the most common clay mineral, to calculate $\Delta \mathrm{H}_{\mathrm{T}}^{\mathrm{o}}, \Delta \mathrm{G}_{\mathrm{T}}{ }^{\mathrm{o}}$, the following chemical equations were derived:

$$
\mathrm{Al}_{2} \mathrm{O}_{3} \cdot 2 \mathrm{SiO}_{2} \cdot 2 \mathrm{H}_{2} \mathrm{O} \rightarrow \mathrm{Al}_{2} \mathrm{O}_{3} \cdot 2 \mathrm{SiO}_{2}+2 \mathrm{H}_{2} \mathrm{O}_{\text {gas }}
$$

$\mathrm{Al}_{2} \mathrm{O}_{3} \cdot 2 \mathrm{SiO}_{2} \cdot 2 \mathrm{H}_{2} \mathrm{O}+\mathrm{C}+\mathrm{O}_{2} \rightarrow \gamma-\mathrm{Al}_{2} \mathrm{O}_{3}+2 \mathrm{SiO}_{2}+\mathrm{CO}_{2 \text { gas }}+2 \mathrm{H}_{2} \mathrm{O}_{\text {gas }}$

$\mathrm{Al}_{2} \mathrm{O}_{3} \cdot 2 \mathrm{SiO}_{2} \cdot 2 \mathrm{H}_{2} \mathrm{O}+2 \mathrm{NaOH} \rightarrow 2\left(\mathrm{Na}_{2} \mathrm{O} \cdot \mathrm{SiO}_{2}\right)+$ $+\gamma-\mathrm{Al}_{2} \mathrm{O}_{3}+2 \mathrm{H}_{2} \mathrm{O}_{\text {gas }}$

$\mathrm{Al}_{2} \mathrm{O}_{3} \cdot 2 \mathrm{SiO}_{2} \cdot 2 \mathrm{H}_{2} \mathrm{O}+2 \mathrm{NaOH}+\mathrm{C}+\mathrm{O}_{2} \rightarrow 2\left(\mathrm{Na}_{2} \mathrm{O} \cdot \mathrm{SiO}_{2}\right)+$ $+\gamma-\mathrm{Al}_{2} \mathrm{O}_{3}+\mathrm{CO}_{2 \text { gas }}+3 \mathrm{H}_{2} \mathrm{O}_{\text {gas }}$

$0.07 \mathrm{Al}_{2} \mathrm{O}_{3} \cdot 2 \mathrm{SiO}_{2} \cdot 2 \mathrm{H}_{2} \mathrm{O}+0.28 \mathrm{NaOH}+0.47 \mathrm{C}+0.47 \mathrm{O}_{2} \rightarrow$ $\rightarrow 0.14\left(\mathrm{Na}_{2} \mathrm{O} \cdot \mathrm{SiO}_{2}\right)+0.07 \gamma-\mathrm{Al}_{2} \mathrm{O}_{3}+0.47 \mathrm{CO}_{2 \mathrm{gas}}+0.28 \mathrm{H}_{2} \mathrm{O}_{\text {gas }}$

The results of the heat effect calculation $\Delta \mathrm{H}_{\mathrm{T}}^{\mathrm{o}}$ (tab. 1), by means of which the amount of generated or absorbed heat can be determined, demonstrate [5] that the carbon and $\mathrm{Na}(\mathrm{OH})$ content in the additive intensifies the destruction of the clay minerals' structure, and the loss of chemically bound water takes place at the lower temperatures. It is confirmed by experimental findings and calculations of $\Delta \mathrm{G}_{\mathrm{T}}{ }^{\circ}$ (fig. 4).

As with the increase of the temperature, the crystalline lattice order increases, it results in the entropy increment. As the decomposition of clay minerals is associated with the increase of gas phase in the system, this determines the chemical reaction pathway. The presence of carbon in the system at high temperatures contributes to the increase of the heat effect of the reaction, which must be taken into account in thermodynamic calculations of reactions, which take place at high temperatures in the presence of carbon [11].

TABLE 1. The dependence of $\Delta \mathrm{H}_{\mathrm{T}}{ }^{\circ}$ on the temperature

\begin{tabular}{|c|c|c|c|}
\hline \multirow{2}{*}{ Reaction } & \multicolumn{3}{|c|}{ The value of $\Delta \mathbf{H}_{\mathrm{T}}{ }^{\mathbf{O}}$ in $\mathbf{k J} / \mathbf{m o l e}$ at temperatures, } \\
\cline { 2 - 4 } & $\mathbf{2 0 0}$ & $\mathbf{3 2 7}$ & $\mathbf{4 5 2}$ \\
\hline 1 & 347.72 & -348.71 & -347.98 \\
2 & -46.03 & -53.18 & -79.88 \\
3 & -232.12 & -234.14 & -232.48 \\
4 & -58.41 & -72.01 & -84.48 \\
5 & -80.52 & -100.29 & -119.14 \\
6 & -167.51 & -168.58 & -170.13 \\
\hline
\end{tabular}

The results of $\Delta \mathrm{H}^{\mathrm{o}}{ }_{\mathrm{T}}$ calculation show that the dehydration reaction (1) of kaolinite without additives is an endothermic process. When introducing the carbon-bearing additive, the same dehydration reaction $(2,3)$ proceeds with the heat release $\Delta \mathrm{H}^{\mathrm{o}}{ }_{\mathrm{T}}<0$. So, carbon is combusted in the presence of oxygen, and this heat destroys the minerals' crystalline lattice.

The presence of alkalies intensifies many high-temperature physical and chemical synthesis processes, including the dehydration of clay minerals. Besides, with the increase of temperature, the amount of generated heat increases as well. The introduction of the complex additive, consisting of carbon and sodium hydroxide (fig. 4, curve 5), accelerates the kaolinite dehydration process substantially. 


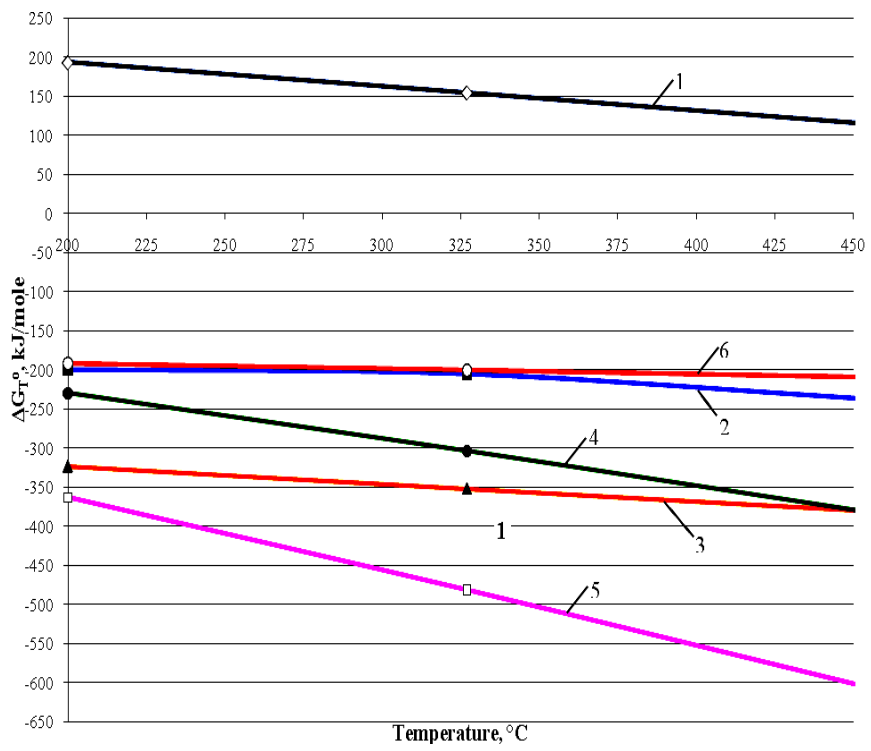

Fig. 4. The dependence of $\Delta \mathrm{GT}$ o on temperature reactions 1-6

The additive, containing carbon and sodium hydroxide, accelerates the kaolinite dehydration process and the amount of the released heat makes up 80.52-119 $\mathrm{kJ} / \mathrm{mole}$ in the temperature interval of $200-452{ }^{\circ} \mathrm{C}$; taking into account the ratio of carbon and $\mathrm{Na}(\mathrm{OH})$ content in the additive and its appending percent, the $\Delta \mathrm{H}^{\mathrm{O}}{ }_{\mathrm{T}}$ amounts to $166.34-168.43$ $\mathrm{kJ} / \mathrm{mole}$.

The calculation findings of the value of $\Delta \mathrm{G}_{\mathrm{T}}{ }^{\mathrm{o}}$ depending on the temperature are presented in Fig. 4, which confirms the intensifying of the dehydration process of kaolinite as a clay mineral; reactions 2-6 proceed from left to right in the considered temperature interval, while reaction 1 of dehydration does not take place without the additive $\left(\Delta \mathrm{G}_{\mathrm{T}}{ }^{\circ}>0\right)$. The possibility of kaolinite decomposition products' formation and compounds' formation in the presence of the additive without taking into account the appending percent (reaction 5) which is higher than when taking it into account (reaction 6), but it takes place in both cases.

The activation energy of the kaolinite dehydroxylation process amounts to $104 \mathrm{~kJ} /$ mole at vapor pressure $600 \mathrm{~Pa}$; and for montmorillonite and illite, it amounts to 62.6 and 51.9 $\mathrm{kJ} / \mathrm{mole}$, respectively [8]. It allows making a conclusion that the removal of structural hydroxyl groups (dehydration) of montmorillonite and illite proceeds at lower energy consumption. As the thermodynamic calculations confirmed the intensification of the kaolinite dehydration process in the presence of coal-alkaline additive, taking into account the activation energy of clay minerals dehydroxylation, it is obvious that the introduction of the coal-alkaline additive into the mix contributes even more to the removal of chemically bound water from montmorillonite and illite than from kaolinite, which is confirmed by DTA method data (fig. 3).

Shein V.I. and others presented a thermodynamic model of portland cement clinker production [11] on the base of the conventional raw mix of a carbonate component and a clay component, which contains kaolinite, $\mathrm{Fe}_{2} \mathrm{O}_{3}, \mathrm{SiO}_{2}$. It was determined that at temperature $756{ }^{\circ} \mathrm{C}$, there is a possibility of
$12 \mathrm{CaO} \cdot \mathrm{Al}_{2} \mathrm{O}_{3}$ and $\beta-\mathrm{CaO} \cdot \mathrm{SiO}_{2}$ formation in the system, and beginning from temperature $790{ }^{\circ} \mathrm{C}-$ of $8 \mathrm{CaO} \cdot \mathrm{Al}_{2} \mathrm{O}_{3} \cdot \mathrm{Fe}_{2} \mathrm{O}_{3}$ and $\beta-\mathrm{CaO} \cdot \mathrm{SiO}_{2}$.

There are literature data about the intensification of the decarbonization process in the presence of alkaline oxides, which results in the temperature interval shift to the range of lower temperatures $\left(830-850{ }^{\circ} \mathrm{C}\right)$ [5]. The coal-alkaline additive in the amount of $0.9 \%$ not only intensifies the process of clay minerals dehydration but also causes decarbonization. The temperature of $\mathrm{CaCO}_{3}$ decomposition is lowered by $\sim 20^{\circ}$ (endothermic effect $-800{ }^{\circ} \mathrm{C}$ ); and the processes of aluminates, calcium ferrites and dicalcium silicate formation, as a result of solid-phase reactions, stop at temperature $\sim 1250-1270{ }^{\circ} \mathrm{C}$.

After dehydration of clays and decarbonization of $\mathrm{CaCO}_{3}$ when baking the portland cement raw mix, the exothermic reactions of aluminates' and calcium silicates' formation take place; calcium meta-aluminate and dicalcium silicate are the first to be formed. As the most important clinker mineral among the aluminates is tricalcium aluminate, it is necessary to determine its formation possibility as well. Taking into account the content of $\mathrm{C}_{67} \mathrm{H}_{67} \mathrm{O}_{30} \mathrm{~N}_{3}(\mathrm{COOH})_{5}$ and $\mathrm{Na}(\mathrm{OH})$ in the coalalkaline additive, the reactions of $2 \mathrm{CaO} \cdot \mathrm{SiO}_{2}, \mathrm{CaO} \cdot \mathrm{Al}_{2} \mathrm{O}_{3}$ and $3 \mathrm{CaO} \cdot \mathrm{Al}_{2} \mathrm{O}_{3}$ formation in the presence of the additive's components (reactions 1-4) and with account of its amount and the ratio of clay and carbonate components in the initial mix (reactions 5-6) have been derived:

$5 \mathrm{CaCO}_{3}+\mathrm{Al}_{2} \mathrm{O}_{3} \cdot 2 \mathrm{SiO}_{2} \cdot 2 \mathrm{H}_{2} \mathrm{O} \rightarrow$

$\rightarrow 2\left(\beta-2 \mathrm{CaO} \cdot \mathrm{SiO}_{2}\right)+\mathrm{CaO} \cdot \mathrm{Al}_{2} \mathrm{O}_{3}+5 \mathrm{CO}_{2 \text { gas }}+2 \mathrm{H}_{2} \mathrm{O}_{\text {vapor }}$

$7 \mathrm{CaCO}_{3}+\mathrm{Al}_{2} \mathrm{O}_{3} \cdot 2 \mathrm{SiO}_{2} \cdot 2 \mathrm{H}_{2} \mathrm{O} \rightarrow$

$\rightarrow 2\left(\beta-2 \mathrm{CaO} \cdot \mathrm{SiO}_{2}\right)+3 \mathrm{CaO} \cdot \mathrm{Al}_{2} \mathrm{O}_{3}+7 \mathrm{CO}_{2 \text { gas }}+2 \mathrm{H}_{2} \mathrm{O}_{\text {vapor }}$

$5 \mathrm{CaCO}_{3}+\mathrm{Al}_{2} \mathrm{O}_{3} \cdot 2 \mathrm{SiO}_{2} \cdot 2 \mathrm{H}_{2} \mathrm{O}+2 \mathrm{NaOH}+\mathrm{C}+\mathrm{O}_{2 \text { gas }} \rightarrow$ $\rightarrow 2\left(\beta-2 \mathrm{CaO} \cdot \mathrm{SiO}_{2}\right)+\mathrm{CaO} \cdot \mathrm{Al}_{2} \mathrm{O}_{3}+\mathrm{Na}_{2} \mathrm{O}+6 \mathrm{CO}_{2 \text { gas }}+3 \mathrm{H}_{2} \mathrm{O}_{\text {vapor }}$

$7 \mathrm{CaCO}_{3}+\mathrm{Al}_{2} \mathrm{O}_{3} \cdot 2 \mathrm{SiO}_{2} \cdot 2 \mathrm{H}_{2} \mathrm{O}+2 \mathrm{NaOH}+\mathrm{C}+\mathrm{O}_{2 \mathrm{gas}} \rightarrow$ $\rightarrow 2\left(\beta-2 \mathrm{CaO} \cdot \mathrm{SiO}_{2}\right)+3 \mathrm{CaO} \cdot \mathrm{Al}_{2} \mathrm{O}_{3}+\mathrm{Na}_{2} \mathrm{O}+8 \mathrm{CO}_{2 \text { gas }}+3 \mathrm{H}_{2} \mathrm{O}_{\text {vapor }}$

$8 \mathrm{CaCO}_{3}+0.8 \mathrm{Al}_{2} \mathrm{O}_{3} \cdot 2 \mathrm{SiO}_{2} \cdot 2 \mathrm{H}_{2} \mathrm{O}+0.006 \mathrm{NaOH}+0.0056 \mathrm{C}+$ $+0.0028 \mathrm{O}_{2 \mathrm{gas}} \rightarrow 1.6\left(\beta-2 \mathrm{CaO} \cdot \mathrm{SiO}_{2}\right)+0.8 \mathrm{CaO} \cdot \mathrm{Al}_{2} \mathrm{O}_{3}+$

$+0.003 \mathrm{Na}_{2} \mathrm{O}+8.0056 \mathrm{CO}_{2 \text { gas }}+1.603 \mathrm{H}_{2} \mathrm{O}_{\text {vapor }}+4 \mathrm{CaO}_{\text {free }}$

$8 \mathrm{CaCO}_{3}+0.8 \mathrm{Al}_{2} \mathrm{O}_{3} \cdot 2 \mathrm{SiO}_{2} \cdot 2 \mathrm{H}_{2} \mathrm{O}+0.006 \mathrm{NaOH}+0.0056 \mathrm{C}+$ $+0.0028 \mathrm{O}_{2 \mathrm{gas}} \rightarrow 1.6\left(\beta-2 \mathrm{CaO} \cdot \mathrm{SiO}_{2}\right)+0.8\left(3 \mathrm{CaO} \cdot \mathrm{Al}_{2} \mathrm{O}_{3}\right)+$ $+0.003 \mathrm{Na}_{2} \mathrm{O}+8.0056 \mathrm{CO}_{2 \mathrm{gas}}+1.603 \mathrm{H}_{2} \mathrm{O}_{\text {vapor }}+2.4 \mathrm{CaO}_{\text {free }}$

Using the thermodynamic properties of the compounds, the value of $\Delta \mathrm{G}_{\mathrm{T}}{ }^{\mathrm{o}}$ of behavior possibility of reactions 1-6 in the temperature interval of $850-1200{ }^{\circ} \mathrm{C}$ was calculated, where decarbonization processes and the substances' interaction in the solid phase take place.

The value of $\Delta \mathrm{G}_{\mathrm{T}}{ }^{\mathrm{o}}$ for the above-mentioned chemical equations (7-12) can be calculated by the following equations:

$\Delta \mathrm{G}_{\mathrm{T}}{ }^{\mathrm{o}}=793196.8+32.81 \cdot \mathrm{T} \cdot \ln \mathrm{T}+38.08 \cdot 10^{-3} \cdot \mathrm{T}^{2}-29.65 \cdot 10^{5} \cdot \mathrm{T}^{-1}$ $-1516.63 \cdot \mathrm{T}$

(reaction 7)

$\Delta \mathrm{G}_{\mathrm{T}}{ }^{\mathrm{o}}=577900+11.46 \cdot \mathrm{T} \cdot \ln \mathrm{T}+14.65 \cdot 10^{-3} 3 \cdot \Delta \mathrm{b} \cdot \mathrm{T}^{2}-5.28 \cdot 10^{5} \cdot \mathrm{T}^{-1}$ $-1427.0 \cdot \mathrm{T}$

(reaction 8 ) 
$\Delta \mathrm{G}_{\mathrm{T}}{ }^{\mathrm{o}}=146922.62+14.68 \cdot \mathrm{T} \cdot \ln \mathrm{T}+4.49 \cdot 10^{-3} \cdot \mathrm{T}^{2}-8.92 \cdot \mathrm{T}^{-1}$ $-432.58 \cdot \mathrm{T}$

(reaction 9)

$\Delta \mathrm{G}_{\mathrm{T}}{ }^{\mathrm{o}}=238036.56-2.06 \cdot \mathrm{T} \cdot \ln \mathrm{T}+5.33 \cdot 10^{-3} \cdot \mathrm{T}^{2}-5.6 \cdot 10^{5} \cdot \mathrm{T}^{-1}$

$-402.68 \mathrm{~T}$

(reaction 10)

$\Delta \mathrm{G}_{\mathrm{T}}{ }^{\mathrm{o}}=2382643.35+60.50 \cdot \mathrm{T} \cdot \ln \mathrm{T}+2.3210^{-3} \cdot \mathrm{T}^{2}-0.5 \cdot 49.48 \cdot \mathrm{T}^{-1}$ $-5412.6 \mathrm{~T}$

(reaction 11)

$\Delta \mathrm{G}_{\mathrm{T}}{ }^{\mathrm{o}}=2405899.01+50.50 \cdot \mathrm{T} \cdot \ln \mathrm{T}+14.96 \cdot 10^{-3} \cdot \mathrm{T}^{2}-0.5 \cdot 46.45 \cdot \mathrm{T}^{-1}$ $-5537.6 \cdot \mathrm{T}$ (reaction 12).

The calculation results of $\Delta \mathrm{G}_{\mathrm{T}}{ }^{\mathrm{o}}$, depending on the temperatures of the mentioned reactions $7-12$, are presented in table 2 and in fig. 5 .

TABLE 2. The dependence of $\Delta \mathrm{G}_{\mathrm{T}}{ }^{\circ}$ on the temperature

\begin{tabular}{|c|c|c|c|c|c|}
\hline \multirow{2}{*}{ Reaction } & \multicolumn{5}{|c|}{ The value of $\Delta \mathbf{G}_{\mathbf{T}}{ }^{\mathbf{0}}$ in $\mathbf{k J} / \mathbf{m o l e}$ at temperatures, ${ }^{\circ} \mathbf{C}$} \\
\cline { 2 - 6 } & $\mathbf{7 2 7}$ & $\mathbf{8 2 7}$ & $\mathbf{1 0 2 7}$ & $\mathbf{1 1 2 7}$ & $\mathbf{1 2 2 7}$ \\
\hline 7 & -102.5 & -124.1 & $-174,3$ & -213.4 & -280.0 \\
8 & -77.3 & -93.5 & $-164,5$ & -186.5 & -240.7 \\
9 & -180.6 & -228.8 & $-281,1$ & -360.9 & -481.7 \\
10 & -174.2 & -219.5 & $-301,7$ & -342.7 & -383.6 \\
11 & -210.0 & -311.1 & $-412,8$ & -410.3 & -390.0 \\
12 & -340.0 & -390.9 & $-441,8$ & -467.2 & -492.6 \\
\hline
\end{tabular}

As a rule, when the temperature increases, the possibility of compounds formation as a result of solid-phase reactions increases as well, which is confirmed with calculation data of $\Delta \mathrm{G}_{\mathrm{T}}^{\mathrm{O}}$ for reactions 7,8 . The presence of carbon and alkaline agent $\mathrm{NaOH}$ intensifies the formation of $\beta-2 \mathrm{CaO} \cdot \mathrm{SiO}_{2}$, calcium aluminates $\mathrm{CaO} \cdot \mathrm{Al}_{2} \mathrm{O}_{3}$ and $3 \mathrm{CaO} \cdot \mathrm{Al}_{2} \mathrm{O}_{3}$. With account of the initial components ratio and the appending percent of the coal-alkaline additive, the value of $\Delta G^{\circ}{ }_{T}$ exceeds $\mid-400$ $\mathrm{kJ} / \mathrm{mole}$, amounting at temperature $1127{ }^{\circ} \mathrm{C}$ to $(-410.3)$ and (467.2) $\mathrm{kJ} / \mathrm{mole}$, and at temperature $1227^{\circ} \mathrm{C}$ - to (-390.0) and (492.6) $\mathrm{kJ} / \mathrm{mole}$ for $\mathrm{CaO} \cdot \mathrm{Al}_{2} \mathrm{O}_{3}$ and $3 \mathrm{Ca} \cdot \mathrm{Al}_{2} \mathrm{O}_{3}$ compounds, respectively.

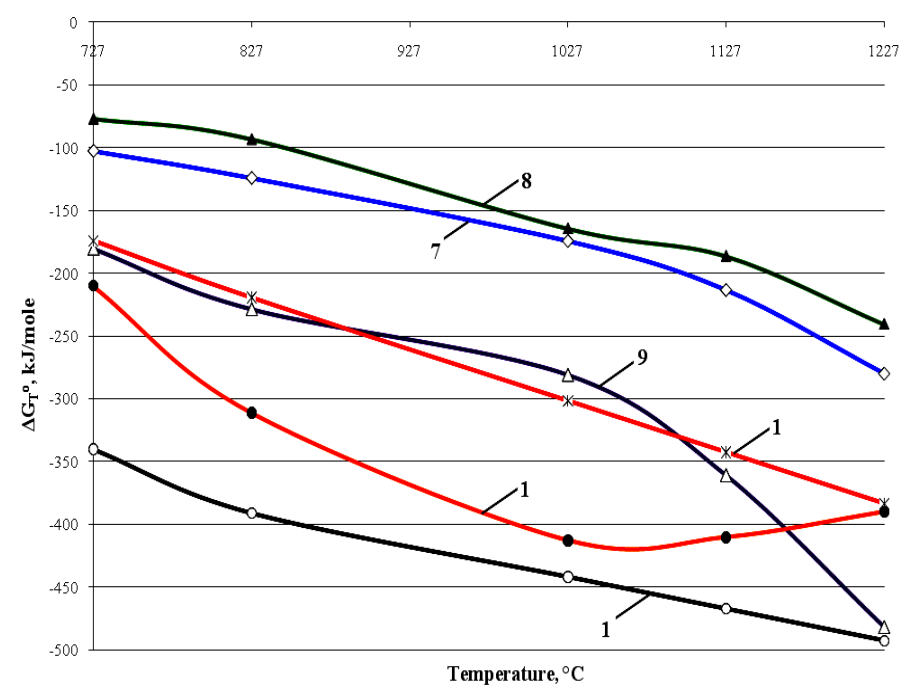

Fig. 5. $\Delta \mathrm{G}_{\mathrm{T}}{ }^{\mathrm{o}}$ depending on reaction temperatures 7-12.

On the basis of the obtained thermodynamic calculation data, the intensifying effect of the coal-alkaline additive on the process of clinker minerals formation $-\beta-2 \mathrm{CaO} \cdot \mathrm{SiO}_{2}$, $\mathrm{CaO} \cdot \mathrm{Al}_{2} \mathrm{O}_{3}$ and $3 \mathrm{CaO} \cdot \mathrm{Al}_{2} \mathrm{O}_{3}$, has been confirmed. The increase of $\Delta \mathrm{G}_{\mathrm{T}}^{\mathrm{o}}$ at temperature $1227{ }^{\circ} \mathrm{C}$ for reaction 11 is conditioned by the reduction of the possibility of calcium meta-aluminate $\mathrm{CaO} \cdot \mathrm{Al}_{2} \mathrm{O}_{3}$ formation due to the increase of possibility of tricalcium aluminate $3 \mathrm{CaO} \cdot \mathrm{Al}_{2} \mathrm{O}_{3}$ formation (a decrease of $\Delta \mathrm{G}_{\mathrm{T}}^{\mathrm{o}}$ for reaction 12 at the same temperature).

\section{CONCLUSION}

According to thermodynamic calculations by Babushkin V.I. [10], the process of $\mathrm{CaCO}_{3}$ decarbonization begins at temperature $887{ }^{\circ} \mathrm{C}$ and the formation of $2 \mathrm{CaO} \cdot \mathrm{SiO}_{2}-$ as a result of the reaction between $\mathrm{CaCO}_{3}$ and $\mathrm{SiO}_{2}$ at the temperature over $462{ }^{\circ} \mathrm{C}$. Reaction 1 of $2 \mathrm{CaO} \cdot \mathrm{SiO}_{2}$ and $\mathrm{CaO} \cdot \mathrm{Al}_{2} \mathrm{O}_{3}$ formation begins at $400{ }^{\circ} \mathrm{C}$ and proceeds from left to right in the considered temperature interval. The presence of the coal-alkaline additive intensifies the compounds' formation processes considerably, and the $\Delta \mathrm{G}_{\mathrm{T}}{ }^{\mathrm{o}}$ is substantially reduced. In the range of higher temperatures, the formation of $2 \mathrm{CaO} \cdot \mathrm{SiO}_{2}$ and $\mathrm{CaO} \cdot \mathrm{Al}_{2} \mathrm{O}_{3}$ compounds becomes more preferable, and up to $1227^{\circ} \mathrm{C}, 3 \mathrm{CaO} \cdot \mathrm{Al}_{2} \mathrm{O}_{3}$ is the most stable among the aluminates.

\section{INFERENCE}

Both the experimental data and the theoretical calculations have confirmed the efficiency of coal-alkaline additive usage not only due to the improvement of slurries' rheological properties but also as a result of its intensifying effect on the processes of clay minerals dehydration, decarbonization and mineral formation in the process of baking.

\section{References}

[1] V. Eitel, The physical chemistry of silicates. M.: The Foreign Literature publishing house, 1962, pp. 1056.

[2] A.P. Osokin, V.G. Akimov, V.N. Panyushkin, "The integrated thermochemical activation of clinker formation process in the portland 
cement technology", The current issues of building materials science. Proceedings of the $7^{\text {th }}$ academic readings of RAACS. P.1. Belgorod, pp. 403-405, 2001.

[3] Cheng Hongfei, Yang Jing, Liu Qinfu, He Junkai, L. Frost Ray, Thermogravimetric analysis-mass spectrometry (TG-MS) of selected Chinese kaolinites. Thermochimica Acta, 507-508 (10), pp. 106-114, 2010.

[4] P.V. Besedin, O.A. Panova, "Thermal gravimetric analysis of plasticizing agents' effect on decarbonization of chalk and raw mix", Cement and its application, vol. 5, pp. 86-91, 2014.

[5] N.P. Bushueva, O.A. Panova, "The energy aspects of coal-alkaline additive's effect on dehydration of clay minerals", Bulletin of BSTU named after V.G. Shukhov, vol. 8, pp. 180-184, 2016.

[6] I. Prigozhin, R. Defey, Chemical thermodynamics. Novosibirsk: Nauka, Siberian department, 1966, p. 512.

[7] L. Kosa, I. Nerád, K. Adamkovičová, I. Proks, "Determination of the heat capacity, enthalpy and entropy of crystallisation of ternary eutectic melt in the system $3 \mathrm{CaO} \cdot 2 \mathrm{SiO}_{2}\left(\mathrm{C}_{3} \mathrm{~S}_{2}\right)-\mathrm{CaO} \cdot \mathrm{SiO}_{2}(\mathrm{CS})$ $2 \mathrm{CaO} \cdot \mathrm{Al}_{2} \mathrm{O}_{3} \cdot \mathrm{SiO}_{2}\left(\mathrm{C}_{2} \mathrm{AS}\right)$ ", Thermochimica Acta, vol. 302(1-2), pp. 189$193,1997$.

[8] M. Brown, D. Dollimore, A. Galway, Reactions in the Solid State, Trans. from Eng. by V.B. Okhotnikov, ed. by Boldyrev V.V. M.: Mir, 1983, p. 162.

[9] D.T. Beruto, W. Searcy Alan, Kim Mun Gyu, "Microstructure, kinetic, structure, thermodynamic analysis for calcite decomposition: free-surface and powder bed experiments", Thermochimica Acta, vol. 424(1-2), pp. 99-109, 2004

[10] V.I. Babushkin, G.M. Matveev, O.P. Mchedlov-Petrosyan, Thermodynamics of silicates. The $4^{\text {th }}$ edition, revised and enlarged. M.: Stroyizdat, 1986, p. 408.

[11] V.I. Shein, T.Yu. Schetkina," Thermodynamic model of portland cement clinker synthesis", Cement and its application, pp. 20-24, 2001. 